\title{
True Surgical Cases in Homeopathy
}

\section{A Different Territory}

\author{
Niraj Parikh ${ }^{1}$ \\ ${ }^{1}$ India \\ Homœopathic Links 2015;28(1):27-32.
}

\begin{abstract}
Address for correspondence Dr. Niraj Parikh, 35, Greenvilla comp, H. B. Kapadiya School Road, Gurukul Road, Memnagar, Ahmedabad 380052, Gujarat, India (e-mail: krishnaclinic@yahoo.co.in).
\end{abstract}
Abstract
Keywords
- Surgical cases
- Limitations
- Lycopodium clavus
- Berberis vulgaris
- Calcarea carbonica
- lodum
- Selenium metallicum

I have failed to give result in many surgical cases, which according to knowledge of allied subjects should be managed conservatively. On the other hand, here I present surgical cases from my last few years of clinical practice in which the conventional system of medicine had to offer nothing less than surgery, but all cases were well managed by homeopathic treatment, evident by reports of appropriate investigation. This warrants further studies to prove and/or lectures by more senior homeopaths to describe more precisely the territory of scope and limitation of homeopathy in surgical cases.

\section{Introduction}

While studying allied subjects, particularly principles and practice of surgery in conventional medicine, a student of homeopathy has always been taught that surgical conditions, especially those with advanced pathological changes, cannot be managed with homeopathy. They require surgery. However, the territory of pure surgical cases in homeopathy is not the same as that of the conventional system of medicine. ${ }^{1-3}$ There are many conditions in which the textbooks of allied subjects mention surgery as the only option and there are many cases in which the allopathic doctor offers surgery as the only option to the patients. Nevertheless, there are a substantial number of reports on such cases well managed with homeopathy only. Quite a few of these patients do not return to the practice at all, and with some others we cannot get proper follow-up information and ultimately we land up with lack of evidence.

In my private practice I could find a few case records with follow-up reports to serve as a proof. In each case the remedy was decided on the basic of the totality of the symptoms after thorough case taking. In the following examples, I show briefly how the repertorisation of the guiding symptoms directed me toward the indicated remedy.

\section{Cases of Urinary Calculi}

As the diameter of the ureter reduces toward the vesicoureteric junction, stones of larger than $5 \mathrm{~mm}$ diameter are not expected to pass by conservative management and the patient is advised to go for lithotripsy or surgery directly. ${ }^{3-5}$ However, many records show easy passage of up to 8 -mm-sized urinary stones with homeopathic treatment only. Moreover, many homeopaths such as I may have encountered patients with urinary stones larger than $8 \mathrm{~mm}$ that were removed by homeopathic treatment. I present here two cases.

\section{Case 1}

On December14, 2010, a 38-year-old man presented with the following complaints:

Once a week he had severe paroxysmal pain from the right loin to the groin increasing in severity.

He had lived an absolutely sedentary life style for the last 1 to 2 years.

Sedentary habits cause early osteoporosis. The lack of physical activity of this patient leads to demineralisation of the bones, and because of increased rate of excretion of calcium salts through his kidneys, deposition of calculus occurs. 
Table 1 Repertorial sheet case 1

\begin{tabular}{|c|c|c|c|c|c|c|c|c|c|c|}
\hline & Lyc. & Nux-v. & Sep. & Anac. & Ign. & Aur. & Bry. & Sil. & Aloes \\
\hline & & 1 & 2 & 3 & 4 & 5 & 6 & 7 & 8 & 9 \\
\hline & & $\begin{array}{l}9 \\
27\end{array}$ & $\begin{array}{l}7 \\
16\end{array}$ & $\begin{array}{l}7 \\
13\end{array}$ & $\begin{array}{l}7 \\
10\end{array}$ & $\begin{array}{l}5 \\
13\end{array}$ & $\begin{array}{l}5 \\
11\end{array}$ & $\begin{array}{l}5 \\
10\end{array}$ & $\begin{array}{l}5 \\
8\end{array}$ & $\begin{array}{l}5 \\
5\end{array}$ \\
\hline 1. Mind, ailments from anger, suppressed & $2 / 37$ & 3 & 1 & - & 1 & - & - & - & 1 & - \\
\hline 2. Mind, anger from contradiction & $3 / 51$ & 3 & 2 & 2 & 3 & 1 & 1 & 1 & 3 & 2 \\
\hline 3. General, sedentary habits & $2 / 24$ & 2 & 1 & 3 & 1 & 1 & 1 & 1 & - & 2 \\
\hline 4. Kidney pain, ureters, right side & $2 / 13$ & 3 & - & 2 & - & - & - & - & - & - \\
\hline
\end{tabular}

He got angry when he came to know about his transfer to a different department, which he never had liked. He could not express his anger to his superior, which seemed to bring about abdominal pain. I advised him to have an ultrasonography (USG) of the abdomen and pelvis, which gave the following impression: right lower ureteric calculus of 12-mm size at the vesicoureteral junction causing mild back pressure changes.

The selected rubrics are shown in - Table $1 .^{6}$

The patient was given a dose of Lycopodium $200 \mathrm{C}$ and advised to repeat whenever he suffered from an attack of ureteric colic. He was advised to follow up if the occurrence of the pain would increase or else after 1 week.

\section{Follow-up on December 23}

He had suffered two colic attacks of low intensity and passed a stone at the end of the second episode, 5 days earlier.

Advice: USG of the pelvis. Placebo if pain would recur or else after 15-day follow-up.

\section{Follow-up on January 8, 2011}

No complain.

USG shows no abnormality.

Advice: Regular physical exercise and follow-up with any complaints.

The patient is still coming to me with his one or other relative, but he himself has never suffered again.

\section{Case 2}

A 42-year-old man comes on October 22, 2010, complaining of pain in the left lumbar region extending to the inguinal region of increasing severity for the last 15 to 20 days.

Out of the conversation the following sentences about his mental sufferings were used.

"I don't know why, but I feel anxious on rising in the morning for a month or so." "Although I feel restless more or less all the time, it's especially more when I am moving about or when I go for a walk."

Before prescribing I advised the patient to go for USG of his abdomen. During the evening session of my outpatient department (OPD) when he came back with his USG report, he vomited food with severe abdominal cramping pain in my consulting room.

The results of his USG included the following:

- Left lower ureteric calculus, size $10 \mathrm{~mm}$, just $4 \mathrm{~cm}$ proximal to the left vesicoureteral junction with mild back pressure changes.

- Bilateral renal calculus.

The characteristics of his mental and physical condition were repertorised to individualise the case ( $\mathbf{- T a b l e ~} \mathbf{2}$ ).

The therapeutic reputation of Berberis vulgaris prompted me to prescribe it with confidence.

Advice: Berberis vulgaris $200 \mathrm{C}$ to repeat with every colic attack and to come back if the duration or the severity of the pain increases or else after 1 week.

Table 2 Repertorial sheet case 2

\begin{tabular}{|l|l|l|l|l|l|l|l|l|l|l|}
\hline \multicolumn{2}{|c|}{} & Berb. & Lyc. & Kali-c. & Agar & Arg-n. & Canth. & Grat. & Mag-c. & Rhus-t. \\
\cline { 3 - 12 } & & 1 & 2 & 3 & 4 & 5 & 6 & 7 & 8 & 9 \\
\cline { 3 - 14 } & & 6 & 3 & 3 & 3 & 3 & 3 & 3 & 3 \\
3 & 3 & 3 \\
\hline 1. Mind, anxiety, morning rising on & $2 / 5$ & 1 & - & 1 & - & - & - & - & 1 & 1 \\
\hline 2. Mind restlessness, motion agg. & $1 / 2$ & 1 & - & - & - & - & - & - & - & - \\
\hline 3. Kidney pain, ureters, left side & $2 / 15$ & 3 & 1 & - & 1 & 1 & 1 & 2 & - & - \\
\hline 4. Stomach, vomiting, type of food & $1 / 148$ & 1 & 1 & 1 & 1 & 1 & 2 & 3 & 1 & 1 \\
\hline
\end{tabular}




\section{Follow-up on October 30}

The severity of pain reduced, but the attacks came at almost the same interval. However, there was no vomiting after the treatment began.

The pain and contractions are expected as long as there is a stone inside, but the reduced intensity of the suffering indicates that the remedy is working. The patient was given the same treatment with a follow-up and X-ray of the kidney, ureter and bladder (KUB) after 3 days.

\section{Follow-up on November 5}

For the last 4 days, the patient had suffered very mild attacks of pain, but the X-ray showed that radio opaque opacity in left hemipelvis suggests left lower ureteric stone.

Advice: Continue the treatment and return for follow-up after 1 week with X-ray (KUB).

\section{Follow-up on December 19}

The third day after the last follow-up, the patient passed a stone with the next and last episode of the colic attack, and with no complaints thereafter, he could delay the follow-up consultation for 1 month. The X-ray showed no abnormal radio opaque shadow or other abnormality.

\section{Other Surgical Conditions}

\section{Case 3}

A 39-year old woman came on October 2, 2013, for the treatment of menorrhagia and thick leucorrhoea for 2 months, particularly while urinating. During case taking she frequently asked: "Doctor, what am I suffering from?" Though she had not received previous treatment, she still asked, "Why is my white discharge still not getting cured?"

Instead of answering her questions, I asked her:

"What do you think?"

"I am afraid."

"Of what?"

"Can this be due to cancer?"

"Why are you afraid of cancer?"

"Obviously because there is no cure for Cancer."
She was obese with a weight of $84 \mathrm{~kg}$ and still gaining weight.

Considering the chronicity of her leucorrhoea at this age, years after childbirth, I advised her to go for USG of the whole abdomen on the fifth or sixth day of her menstrual cycle to rule out any gross pathology. Positive findings from the USG of the abdomen, including transvaginal sonography, showed bulky growths measuring $121 \times 62 \mathrm{~mm}$ and multiple small hypoechoic areas in fundus, suggesting the possibility of adenomyosis. Endometrial thickness was $8.2 \mathrm{~mm}$.

Prescription: Calcarea carbonica $200 \mathrm{C}$ with placebo twice a day for 1 month.

The rubrics taken from the totality of her symptoms are shown in - Table 3.

\section{Follow-up on November 6}

The leucorrhoea worsened for 2 to 3 days being followed by relief.

The menorrhagia was still as it was.

The patient did not raise any question about her disease, which indicated that her fear of an incurable disease had decreased.

Prescription: Placebo for 1 month and a follow-up appointment after the completion of her next menses.

\section{Follow-up on December 4}

No complaints. The menstrual flow is also reduced to normal.

Prescription: Placebo for 1 month and follow-up with a USG of the abdomen.

\section{Follow-up on February 8, 2014}

No complaints. A USG of the abdomen and a transvaginal USG of the uterus shows normal size, and echo-pattern measures $98 \times 46 \mathrm{~mm}$.

Endometrial thickness is now $6.2 \mathrm{~mm}$, and gallbladder shows small nonmobile nodule suggesting the possibility of a gallbladder polyp.

Table 3 Repertorial sheet case 3

\begin{tabular}{|c|c|c|c|c|c|c|c|c|c|c|}
\hline & Calc. & Phos. & Graph. & Kali-c. & Aur. & Puls. & Apis. & Arn. & Lach. \\
\hline & & 1 & 2 & 3 & 4 & 5 & 6 & 7 & 8 & 9 \\
\hline & & $\begin{array}{l}9 \\
23\end{array}$ & $\begin{array}{l}7 \\
14\end{array}$ & $\begin{array}{l}7 \\
13\end{array}$ & $\begin{array}{l}7 \\
12\end{array}$ & $\begin{array}{l}7 \\
10\end{array}$ & $\begin{array}{l}7 \\
10\end{array}$ & $\begin{array}{l}7 \\
9\end{array}$ & $\begin{array}{l}7 \\
9\end{array}$ & $\begin{array}{l}7 \\
9\end{array}$ \\
\hline $\begin{array}{l}\text { 1. Mind, fear, disease, of impending / } \\
\text { fear, incurable, of being }\end{array}$ & $2 / 46$ & 1 & 1 & 1 & 1 & 1 & 1 & 1 & 1 & 1 \\
\hline 2. General, obesity & $3 / 137$ & 3 & 2 & 3 & 2 & 2 & 2 & 1 & 1 & 1 \\
\hline $\begin{array}{l}\text { 3. Female genitalia/sex, tumours, } \\
\text { uterus, myoma }\end{array}$ & $2 / 73$ & 3 & 3 & 1 & 2 & 1 & 1 & 2 & 2 & 2 \\
\hline $\begin{array}{l}\text { 4. Female genitalia/sex, leucorrhoea, } \\
\text { thick urination, during }\end{array}$ & $2 / 1$ & 3 & - & - & - & - & - & - & - & - \\
\hline
\end{tabular}




\section{Discussion}

The given remedy Calcarea carbonica not only removed her fibroid but also stopped the further progress of the endometrial hyperplasia with the remedy and without surgical intervention. Perhaps eventually her sycotic miasm was inadequately treated, resulting in the development of a benign polyp of the gallbladder, which might already had been there before treatment but was missed in the previous USG due to its small size.

\section{Case 4}

A 65-year-old-man came on December 26, 2009. When the patient sits in front of me, I always wait for some time before asking anything to see whether the patient starts talking himself. If the patient does not begin, only then I invite him to narrate his story by using words with a broad meaning.

Doctor: Tell me now. (I avoid words like "suffering," "problem," etc. to know actually for what the patient is coming and what is important to him.)

"Nothing much doctor; I just have to strain a little before urinating."

"What else?"

"Nothing doctor, but my family complains that I spend more time in the toilet for urination."

"Anything else?"

"No doctor." (The patient's relative tells me that the patient has lost $5 \mathrm{~kg}$ of weight in 2 months' time. Direct questions about prostate hypertrophy were asked considering his age and chief complaint.)

"How frequently do you need to urinate?"

"Yes doctor, I need to urinate slightly more frequently for the last few months."

"How many times a night?"

"Four to five times."

"Do you feel satisfied after urination?"

"Only sometimes, I feel that a little urine remains behind."

During case taking he never volunteered his troubles freely and with every direct question he used words such as "slight," "mild," about his complaints. There was nothing that suggested any fear of the doctor, the hospital, an injury, or aversion for medicine. His appetite was good. On examination I saw that he looked very pale and his weight was $54 \mathrm{~kg}$.
I advised to have a USG of the abdomen, complete blood (cell) count (CBC), erythrocyte sedimentation rate (ESR), red blood (cell) count (RBS) and routine urine microscopy. The blood and urine reports were almost normal.

Positive findings from USG of the abdomen included the following:

- Gallbladder distended with multiple mobile calculi.

- Both kidneys show hydronephrosis hydroureter up to ureterovesical junction.

- Urinary bladder shows changes of cystitis with multiple pseudodiverticula.

- Prostate is enlarged measuring 57.32.

- Postvoid residual urine measures $470 \mathrm{~mL}$.

Except for the cholelithiasis, all abnormalities were pathologically secondary to prostatic hypertrophy. The chosen rubrics are shown in - Table 4.

His dark complexion and thin physical built also indicated Iodum. He was given a dose of Iodum 200C followed by placebo for 1 week.

\section{Follow-up on January 5}

"I am doing better."

"How frequently do you need to urinate?"

"That is still four to five times a night, but the flow starts as soon as I make the effort and it requires much less straining." His weight is $55 \mathrm{~kg}$.

Advice: Placebo for 15 days.

\section{Follow-up on January 22}

"Now I am well."

"What is the frequency of needing to urinate at night?"

"It is still four to five per night." His weight is still $55 \mathrm{~kg}$. Advice: Iodum 200C and placebo for 15 days.

Follow-up on February 12, 2010

"No complaints doctor. I need to wake up only once at night." Weight: $57 \mathrm{~kg}$.

Advice: Placebo for 1 month and a USG of the abdomen.

Follow-up on March 20

"I am fine doctor; see the report."

Table 4 Repertorial sheet case 4

\begin{tabular}{|c|c|c|c|c|c|c|c|c|c|c|}
\hline & lod. & Con & Sulph. & Bar-c. & Sel. & Arm. & Puls. & Dig. & Staph. \\
\hline & & 1 & 2 & 3 & 4 & 5 & 6 & 7 & 8 & 9 \\
\hline & & $\begin{array}{l}9 \\
16\end{array}$ & $\begin{array}{l}6 \\
10\end{array}$ & $\begin{array}{l}6 \\
10\end{array}$ & $\begin{array}{l}5 \\
11\end{array}$ & $\begin{array}{l}5 \\
11\end{array}$ & $\begin{array}{l}4 \\
14\end{array}$ & $\begin{array}{l}4 \\
12\end{array}$ & $\begin{array}{l}4 \\
10\end{array}$ & $\begin{array}{l}4 \\
9\end{array}$ \\
\hline 1. Mind, well, says he is well when very sick & $3 / 21$ & 1 & - & - & - & - & 3 & 3 & - & - \\
\hline 2. General emaciation, with ravenous appetite & $2 / 32$ & 3 & 1 & 2 & 1 & 1 & - & - & - & - \\
\hline 3. General: anaemia & $1 / 204$ & 1 & 2 & 3 & - & - & 2 & 3 & 1 & 3 \\
\hline 4. Prostate gland, swelling, old people, in & $3 / 13$ & 2 & 2 & 1 & 3 & 3 & - & - & 3 & 2 \\
\hline
\end{tabular}


Table 5 Repertorial sheet case 5

\begin{tabular}{|c|c|c|c|c|c|c|c|c|c|c|}
\hline & Sel. & Nux-v. & Staph. & Nat-c. & Gels. & Lyc. & Calc. & Lach. & Sil. \\
\hline & & 1 & 2 & 3 & 4 & 5 & 6 & 7 & 8 & 9 \\
\hline & & $\begin{array}{l}10 \\
30\end{array}$ & $\begin{array}{l}9 \\
19\end{array}$ & $\begin{array}{l}9 \\
19\end{array}$ & $\begin{array}{l}8 \\
22\end{array}$ & $\begin{array}{l}8 \\
19\end{array}$ & $\begin{array}{l}7 \\
19\end{array}$ & $\begin{array}{l}7 \\
17\end{array}$ & $\begin{array}{l}7 \\
17\end{array}$ & $\begin{array}{l}7 \\
15\end{array}$ \\
\hline 1. Mind, mental exertion, agg & $3 / 155$ & 3 & 3 & 3 & 3 & 1 & 3 & 3 & 3 & 3 \\
\hline 2. General, weakness, heat of the sun & $3 / 4$ & 3 & - & - & 3 & 3 & - & - & - & - \\
\hline 3. Bladder, urination, incomplete & $2 / 32$ & 3 & 1 & 1 & 1 & 1 & 1 & 1 & 3 & 1 \\
\hline 4. Prostate gland, swelling, in old people & $2 / 13$ & 3 & 1 & 1 & - & - & - & - & - & - \\
\hline 5. Abdomen, hernia, inguinal & $3 / 80$ & - & 3 & 1 & - & - & 3 & 1 & 1 & 1 \\
\hline
\end{tabular}

Weight: $57 \mathrm{~kg}$.

Findings of the USG:

- Gallbladder is distended and shows two to three mobile calculi of 7 to $9 \mathrm{~mm}$.

- Kidney: No evidence of hydronephrosis or hydroureter on both sides.

- Urinary bladder: Shows thickened wall with multiple trabeculations suggesting cystitis.

The bladder muscles became hypertrophic due to the straining that he needed to do in the previous months. The postvoid residual urine is now $50 \mathrm{~mL}$.

Advice: Placebo for 15 days. Follow up if there is any complain.

This patient has silent gallstones, in a probably badly functioning gallbladder. Therefore, intervention is advised only when he has complaints.

\section{Case 5}

A 68-year-old-man came to my clinic on May 16, 2011.

The patient told: "Even after straining and waiting for enough time I feel unsatisfied and feel that my bladder is still not empty."

"Since when do you have this?"

"For the last 4 months, since I restarted to work again."

"What do you think, why since then?" "I don't know, but after 8 years of being retired I rejoined a job where I need no physical activity. But I have been suffering more since then. The urge to urinate arises as soon as I start to fill in a form for a client, so when I am not occupied mentally, I need to urine less."

"What else?"

"Within a few minutes I feel weakened by a slight heat of the Sun."

Advice: USG of the urinary system with the result of showing:

- A mild to moderate prostatic enlargement 45 to $50 \mathrm{~g}$.

- Postvoid urine is $150 \mathrm{~mL}$.

- The right kidney is not detectable and bilateral inguinal hernia.
The chosen rubrics are shown in - Table 5 .

Although he was 68 years old, he looked like he was in his eighties. These all lead me to prescribe Selenium Metallicum $30 \mathrm{C}$ four times a day once a week, followed by placebo for 2 weeks.

\section{Follow-up on June 15, 2011}

"I still have a sense of incomplete emptying of the bladder, but less frequent urging to urinate. Otherwise I feel well."

Prescription: Placebo for 1 month.

\section{Follow-up on July 17}

"Still a sense of incomplete emptying but only in the morning. No other complaints."

Prescription: Placebo for 1 month.

\section{Follow-up on August 16}

"The sense of incomplete emptying is still there in the morning."

Prescription: Selenium 30C, twice a week, followed by placebo for 1 month.

\section{Follow-up on October 3}

"Much better; the incomplete feeling after urinating occurs only once a week, but worse when I don't go straight for urination when I need to."

Prescription: Placebo for 1 month.

Follow-up on November 6, 2011, January 10, 2012 and

March 18, 2012

No complaints.

Advice: Placebo and USG of the urinary system.

Findings of USG:

- Postvoid urine $30 \mathrm{~mL}$.

- There is an improvement in the size of prostate from 45-50 to $35 \mathrm{~g}$.

The patient was advised not to take medication and followup every 3 months. In the routine health check I found him to have a complete normal prostate. 


\section{Conclusion}

I realise that these are too few examples to convince conventional medicine and to show that our limitations are different from them. We should also admit that with the limitations in our science, other systems might have a solution. In fact, I have many failures in cases of multiple renal stones of shorter than $6 \mathrm{~mm}$ diameter in which simple flush therapy by conventional medicine has removed the stones. Still homeopathy has definitely something to offer to patients who are being advised by other disciplines to have surgery-not only in cases such as these with evidence from pathological reports but also in cases where we don't have pathological reports as proof, such as tonsillitis, chronic suppurative otitis media, deviated nasal septum and warts etc., in which patients can be made free of suffering by homeopathy without surgery.

Although limitations of homeopathy can be based on factors such as vitality, susceptibility and absence of individualising characteristics. Large-scale studies will definitely be helpful in showing the scope and possibilities of homeopathy. They may also explain our limitations in the language of allied science- for example, metastasis in cases of malignancy and size in cases of appendicitis, urinary calculi and benign tumours etc. that are being found in the medical reports available to our patients.

\section{References}

1 Sarkar BK. Treatment of local diseases surgical and non-surgical. Hahnemann's Organon. 5th ed. Calcutta, India: M. Bhattacharya \& Co.; 1960:408

2 Sarkar BK. Discussion about treatment of local affection with more topical employment of medicine. Hahnemann's Organon. 5th ed. Calcutta India: M. Bhattacharya \& Co.; 1960:409-411

3 Sarkar BK. Hahnemann's pathological hypothesis involved in explaining the mechanism of production of local maladies and rational of its treatment by internal administration of suitable homoeopathic drugs. Hahnemann's Organon. 5th ed. Calcutta India: M. Bhattacharya \& Co.; 1960:411-413

4 Bailey HH, Love RJM. The kidneys and ureters. Russell RCG, William NS, Bulstrode CJK. Short Practise of Surgery. 24th ed. London, UK: Hodder Education; 2004:1318

5 Das S. The Kidney and Ureter-A Concise Textbook of Surgery. 5th ed. Calcutta, IndiaDr. S Das. Calcutta2008:1208

6 Synthesis version 9 from Radar 10 Repertory Program. Archibel; Assesse 2009

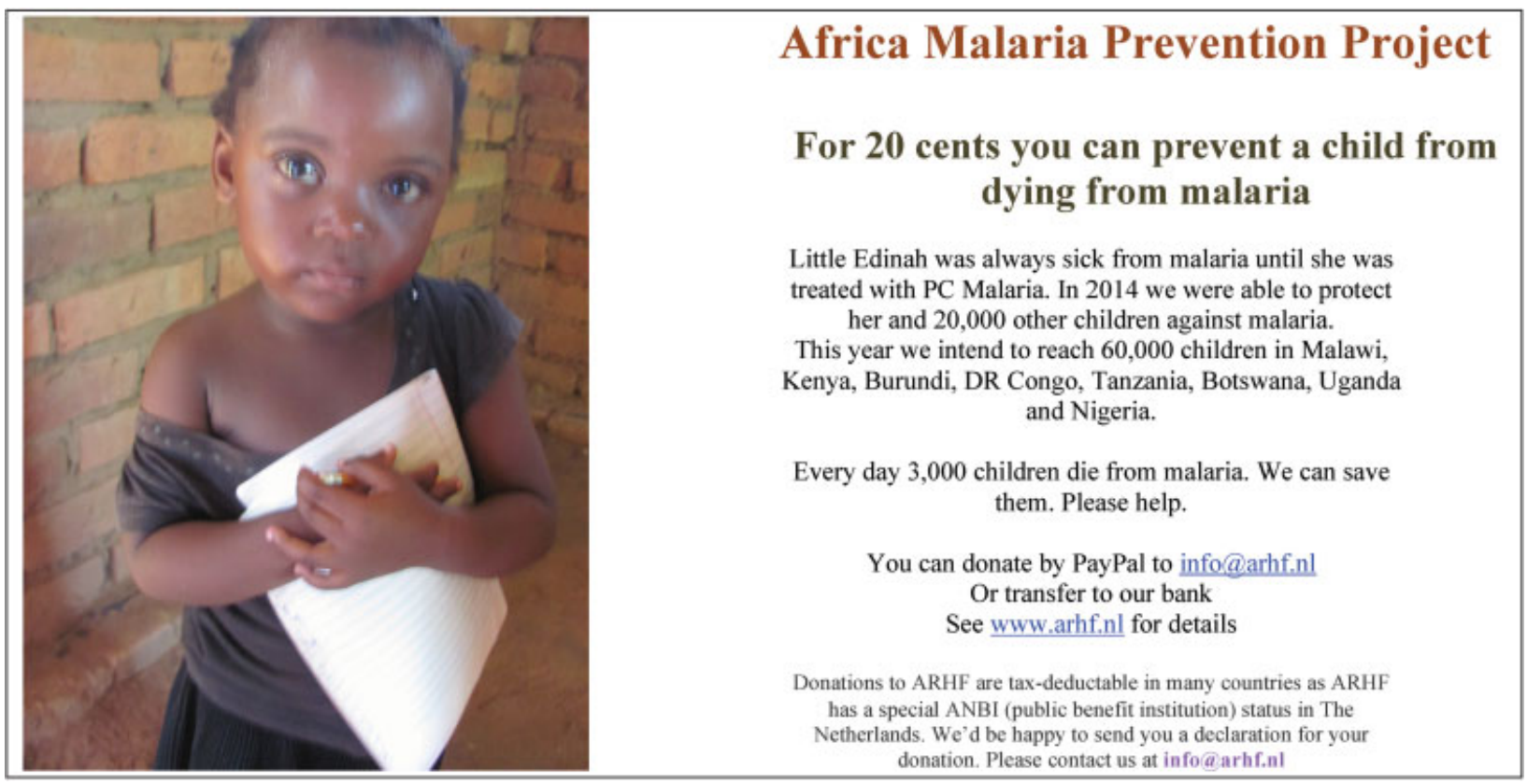

